\title{
Brincando com a Matemática: apropriações e circulação do método de Froebel no Brasil nas primeiras décadas da República
}

\author{
Playing with Mathematics: appropriations and the dissemination \\ of the Froebel method in Brazil in the first decades of the Republic
}

Maria Celia Leme da Silva ${ }^{1}$

Alexsandra Camara²

\author{
'Universidade Federal de São Paulo (UNIFESP), São Paulo, SP, Brasil. \\ Autora Correspondente: celia.leme@unifesp.br \\ ${ }^{2}$ Colégio Nossa Senhora do Rosário, Curitiba, PR, Brasil.
}

Resumo: O presente artigo tem por objetivo analisar as apropriações do método de Froebel no que diz respeito ao ensino de matemática e a sua circulação nos estados do Rio de Janeiro, São Paulo e Paraná. Como fonte de pesquisa, examina-se o método de Froebel, presente no Manual de Menezes Vieira e na Revista do Jardim de Infância, ambas publicadas no século 19 e sua circulação e apropriação. Identifica-se a proximidade do Brasil com estudos sobre o método froebeliano advindos da Europa e dos Estados Unidos por meio de apropriações desenvolvidas em Jardins de Infância. As análises indicam que os dons de Froebel podem ser considerados objetos manipuláveis com intencionalidade educativa. Conclui-se que a história da educação matemática no Brasil precisa revisitar a Educação Infantil, possibilitando novas discussões e práticas relacionadas ao processo de ensino e aprendizagem das crianças pequenas.

Palavras-chave: Ensino de matemática; Jardim de infância; Método Froebel; Modelo pedagógico.

\begin{abstract}
This article aims to analyze the appropriations of the Froebel method with respect to the teaching of mathematics and its dissemination in the states of Rio de Janeiro, São Paulo and Paraná. As a research source, we examine the Froebel method, present in the Manual by Menezes Vieira and in the Revista do Jardim de Infância, both published in the 19th century, and its dissemination and appropriation, with respect to mathematical knowledge. Brazil's proximity to studies on the Froebelian method in Europe and the United States was identified through appropriations developed in kindergartens. The analyses indicate that Froebel's gifts can be considered manipulable objects with an educational intent, especially for the teaching of mathematics. It is concluded that the history of mathematics education in Brazil needs to revisit Early Childhood Education, thus allowing for new discussions and practices related to the teaching and learning process of young children.
\end{abstract}

Keywords: Mathematics teaching; Kindergarten; Froebel method; Pedagogical models. 


\section{Introdução}

Historicamente, a designação Educação Infantil nas normativas é bastante recente em nosso país. Foi somente na Constituição Federal de 1988 que, pela primeira vez na História do Brasil, foi reconhecido o direito à educação para crianças pequenas, quando tanto a creche quanto a pré-escola foram incluídas na política educacional. Entretanto, apenas com a Lei de Diretrizes e Bases (LDB), de 2013, se consagrou plenamente a obrigatoriedade de matrícula de todas as crianças de 4 e 5 anos em Instituições de Educação Infantil (BRASIL, 2018).

A Base Nacional Comum Curricular (BNCC), de 2018, documento mais recente no que se refere ao currículo da Educação Infantil, indica como eixos estruturantes as interações e as brincadeiras, que possibilitam as aprendizagens, o desenvolvimento e a socialização das crianças dessa faixa etária. Além desses eixos, a BNCC assegura seis direitos de aprendizagem e desenvolvimento, relacionados às ações de conviver, brincar, participar, explorar, expressar e conhecer-se. Destaca, por fim, nesse documento a necessidade de imprimir intencionalidade educativa às práticas pedagógicas.

Se, por um lado, o direito à Educação Infantil, assegurado pelas normativas federais, é bastante recente, a sua concepção e a sua importância são muito antigas e têm o alemão Friedrich Froebel (1782-1852) como fundador da ideia de Jardim de Infância ou Kindergarten. Froebel, juntamente com Johann H. Pestalozzi (1746-1827) são personagens relevantes no contexto tanto internacional como nacional, para o processo histórico da formação educacional das crianças pequenas.

Significativa defesa da implantação do Jardim de Infância no Brasil foi realizada por Rui Barbosa, em um parecer apresentado em 1882, na Câmara do Império, sobre a reforma do ensino primário e várias instituições complementares da instrução pública. Para ele, os Jardins iriam contribuir para a formação de uma nova sociedade, e a proposta de Froebel teria o poder formativo necessário para a educação da infância. "Um menino a brincar é sagrado aos meus olhos" (BARBOSA, 1947, p. 81).

Froebel discerniu e avaliou, em toda a extensão das suas consequências, os fatos capitais da Educação Infantil: uma necessidade contínua de movimento, uma simpatia inesgotável pela natureza, um instinto de observação curioso e sutilíssimo, uma tendência invencível para a imitação, uma fantasia infinitamente inventiva. Froebel trabalhou, em 1808, como preceptor na Escola-Modelo em Iverdon (Suíça), onde tomou contato com a obra do educador suíço Pestalozzi. Em 1811, retornou para a Alemanha e estudou ciências naturais na Universidade de Gottingen, período em que formulou sua filosofia da esfera - lei esférica - que fundamentou e influenciou a sua pedagogia escolar no Jardim de Infância (FROEBEL, 2001).

Em 1817, Froebel fundou sua primeira escola, na qual lecionou ciências naturais e matemáticas. No ano de 1826 publicou o livro A educação do homem, arte da educação, da instrução e do ensino, em que teoriza suas experiências pedagógicas. Em 1837, foi o momento da criação do primeiro Jardim de Infância (Kindergarten) e, em 1839, inaugurou o Instituto de Formação de guias da Infância. Em 1840, deu ao seu estabelecimento o nome de Kindergarten, o qual também servia como Escola Normal, pois as jardineiras - nome utilizado por Froebel para nomear as professoras responsáveis pela educação das crianças, que simbolizavam plantas de um jardim - eram ali preparadas (FROEBEL, 2001). 
Em terras brasileiras, de acordo com Gonzalez (2020), a primeira instituição de Educação Infantil foi o Jardim de Infância Emilia Erichsen, criado em 1862 no estado do Paraná; sendo o Jardim de Infância do Colégio Menezes Vieira, no Rio de Janeiro, a segunda instituição, criada em 1875, por Joaquim José de Menezes Vieira (1848-1897) e sua esposa Carlota. Provavelmente foi Menezes Vieira quem produziu e publicou o primeiro manual destinado aos professores de Jardins de Infância. Intitulado Manual para os jardins da infância: ligeira compilação pelo Dr. Menezes Vieira, era um apanhado das obras de Froebel e Marie-Pape-Carpantier (BASTOS, 2011).

Somente em 1896 criou-se o primeiro Jardim de Infância público do país, que funcionou anexo à Escola Normal Caetano de Campos em São Paulo, organizado por Gabriel Prestes. Portanto, neste momento, a proposta de Froebel também circulou pelo estado de São Paulo. A Revista do Jardim da Infância, nas edições de 1896 e de 1897, editadas pelo governo paulista, sob a coordenação de Gabriel Prestes, traz os princípios e os métodos froebelianos.

Juntamente à criação dos Jardins de Infância nos estados do Paraná, Rio de Janeiro e São Paulo, identificam-se diferentes apropriações do método de Froebel. A circulação de propostas pedagógicas no âmbito internacional desempenhou papel relevante na construção de sistemas escolares modernos no século XIX (MATASCI, 2015). No Brasil, país continental, o contato com o estrangeiro se fez presente desde o século XIX e de maneiras distintas, de acordo com a região. Por exemplo, a missão pedagógica de 1891, empreendida por professores do Rio de Janeiro aos países europeus, pode ser lida como um exemplo de movimento de circulação e transferência de ideais. Conceição (2019) investigou os relatórios dos professores viajantes e constatou a presença do ensino froebeliano em muitos países europeus, como Bélgica, Suécia, França, Espanha e Itália. O método de Froebel esteve fortemente presente na Escola de Trabalhos Manuais, da Suécia, a Escola de Nääs, na qual o professor Manoel Frazão realizou cursos de verão. Frazão foi um dos professores brasileiros viajantes, formou-se no curso superior de Matemáticas e Ciências Naturais pela Academia Militar do Rio de Janeiro; foi professor primário e diretor escolar; produziu materiais e livros para uso nas escolas primárias, em 1863 apresentou ao Conselho de Instrução Pública as Postilas de Aritmética, aprovada para uso nas escolas primárias (CONCEIÇÃO, 2019).

A pesquisa de Camara (2019) analisou a presença do métod o froebeliano nas práticas do primeiro Jardim de Infância público do estado do Paraná, o que, provavelmente, teria ocorrido devido à formação realizada pela professora Maria Francisca de Miranda na Escola Normal Caetano de Campos, em São Paulo no ano de 1904.

Pesquisas realizadas por Arce (2002), Bastos (2011), Gonzalez (2020), Kishimoto (1988) e Kuhlmann Jr. (1994) investigaram o ensino voltado às crianças menores de 6 anos e as concepções de Froebel no Brasil. No entanto, tais pesquisas não tiveram o propósito de analisar a proposta relacionada aos saberes matemáticos e como ela foi apropriada em terras brasileiras.

Desta forma, o presente artigo tem por objetivo analisar as apropriações do método de Froebel no que diz respeito ao ensino de matemática e a sua circulação nos estados do Rio de Janeiro, São Paulo e Paraná, no final do século XIX e início do século $\mathrm{XX}$. 


\section{Apropriações do método de Froebel por Menezes Vieira}

O Jardim de Infância do Colégio Menezes Vieira tinha por objetivo atender crianças do sexo masculino, de 3 a 6 anos, que se iniciavam em atividades relacionadas à ginástica, à pintura, ao desenho, aos exercícios de linguagem e de cálculo, à escrita, à leitura, à história, à geografia e à religião. O Manual para os jardins da infância (1882), produzido por Menezes de Vieira e amplamente divulgado pela imprensa da época (GONZALEZ, 2020), foi elaborado com o intuito de divulgar o ideário e as experiências desenvolvidas na Alemanha, na França e na Bélgica. Nenhum exemplar deste manual foi localizado em bibliotecas brasileiras e, somente no ano de 2000, a obra foi identificada na Biblioteca Ferdinan Buisson, do Institut National de Recherche Pédagogique, da França. A historiadora Maria Helena Camara Bastos publicou-o na íntegra pela Redes Editora, em 2011. Uma possibilidade para a obra constar do acervo francês é que ela tenha sido doada pelo autor, durante a Exposição Universal de Paris, em 1889.

Figura 1 - Capa do Manual de Menezes Vieira

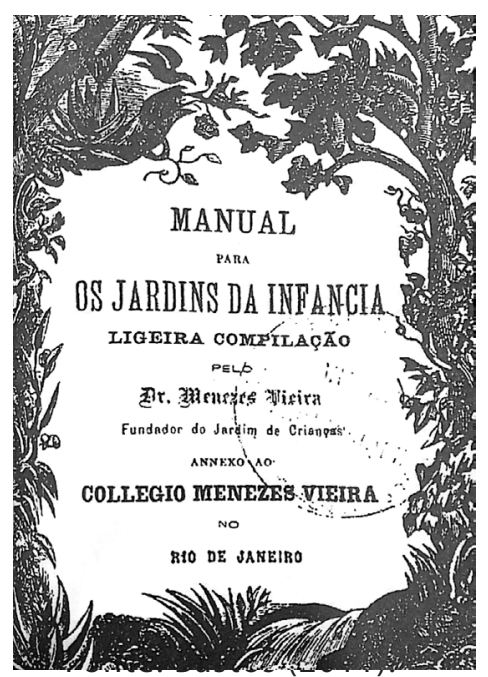

Além de publicar na íntegra o Manual para os jardins da infância no Anexo, Bastos (2011) também analisou o processo de apropriação e nacionalização das inovações pedagógicas propostas pelo Manual. A adaptação do método de Froebel à realidade brasileira se fez necessária, visto o público para o qual se destinava: crianças em cujas artérias pulsava o sangue de três raças: indígena, africana e europeia. Comparando várias obras que tratam do método do Froebel, a historiadora concluiu ser o Manuel pratique des jardins d'enfants de Frédéric Froebel à l'usage des institutrices et des méres de famille, editado em 1874 e, traduzido de documentos alemães pelo professor belga J-F. Jacobs, o mais semelhante à versão brasileira.

O primeiro Manual destinado aos Jardins de Infância publicado no Brasil abre um leque de novas investigações, em particular no que diz respeito à História da Educação Matemática. Uma primeira folheada no índice da parte prática do Manual demonstra o interesse pelo ensino de matemática, mais propriamente, o de geometria. Os primeiros capítulos da obra são organizados, a partir dos dons - brinquedos criados por Froebel, material empregado nas ocupações das crianças. De acordo com Arce (2002), a filosofia do trabalho pedagógico de Froebel era a de uma educação na qual a criança se autoeducasse através de suas atividades: 
Para a realização do autoconhecimento com liberdade, Froebel elege o jogo como seu grande instrumento que, juntamente com os brinquedos, mediaria o autoconhecimento através do exercício de exteriorização e interiorização da essência divina de cada criança. Froebel foi pioneiro por reconhecer o jogo e a brincadeira como as formas que a criança utiliza para expressar como vê o mundo, além de serem geradores do desenvolvimento na primeira infância. [...] Os brinquedos criados para este fim foram chamados de "dons", porque eles seriam uma espécie de "presentes" dados às crianças, ferramentas para ajudá-las a descobrir os seus próprios dons. (ARCE, 2002, p. 59-61, grifos do autor).

O Manual é estruturado em duas partes. A primeira, de divulgação da instituição, portanto mais teórica, organiza-se em três itens: esboço bibliográfico de Frederico Froebel; aos jovens professores, conselhos e recomendações para a condução da prática educativa; e em forma de perguntas e respostas os objetivos, as finalidades e a organização do Manual. A segunda parte, considerada a parte prática, traz orientações metodológicas para o professor trabalhar com os dons de Froebel.

O livro compilado por Menezes Viera apresenta sete dons, sendo que para cada dom há um grupo de exercícios para serem desenvolvidos pelos alunos. Finalizado o estudo com os dons, o livro cita as caixas matemáticas, que correspondem a três caixas com objetos similares aos dons e, novamente, propõe exercícios didáticos para cada uma das caixas. O autor ressalta serem elas destinadas ao ensino elementar do cálculo e da geometria.

Na sequência, o Manual indica outros materiais, do mesmo modo com propostas de exercícios para serem feitos com os alunos: as talas, que envolvem trabalhos de entrelaçamentos; os pauzinhos, que subsidiam exercícios geométricos e de cálculo; e os anéis. Ao final, são fornecidas sugestões de trabalhos manuais também com exercícios, como: modelagem, trabalhos com ervilhas e pauzinhos, tecelagem, dobraduras, entrelaçamentos, recortes, bordados, varetas articuladas, trabalho com papelão e desenho. Vale destacar que o termo modelagem utilizado na época de estudo não apresenta o mesmo significado que o dos dias atuais: um processo dinâmico, utilizado para obtenção e validação de modelos matemáticos. A modelagem a qual se refere a proposta de Froebel está relacionada à construção manual de objetos (com o uso de barro, argila ou massa plástica).

Todos os materiais e exercícios propostos trabalham conceitos geométricos e de cálculo. Pode-se dizer que correspondem aos primeiros passos de contato com a matemática, em forma de brincadeira, com atividades manipulativas e de exploração que se apoiam nos objetos criados (dons) por Froebel.

No ano de 1837, Froebel construiu uma fábrica de brinquedos, que tinha como objetivo criar materiais que auxiliassem na aprendizagem e no desenvolvimento das crianças, elaborando, inclusive, todo um processo de conhecimento e exploração do material. Trata-se de amplo e vasto material para ensino intuitivo de matemática que, por meio de experiências e descobertas, procurava motivar o interesse das crianças; razão pela qual merece ser objeto de investigação da educação matemática (ARCE, 2002).

Neste estudo, apresentam-se e analisam-se somente os 7 dons que constam do livro de Menezes Vieira (1882) (quadros 1, 2 e 3), de modo a melhor compreender o material e como Froebel o utilizou nos exercícios e nas brincadeiras sugeridas. 
Inicia-se o exame do material com os dois primeiros dons, distribuídos no livro da seguinte maneira:

Quadro 1 - Dons de Froebel $\left(1^{\circ}\right.$ e $\left.2^{\circ}\right)$

\begin{tabular}{|c|c|c|}
\hline \multirow{10}{*}{$1^{\circ}$ Dom } & \multirow[t]{10}{*}{ A bola } & $1^{\circ}$ Exercício - Distribuição das bolas \\
\hline & & $2^{\circ}$ Exercício - A forma \\
\hline & & $3^{\circ}$ Exercício - As posições no espaço \\
\hline & & $4^{\circ}$ Exercício - As posições relativas de dois objetos \\
\hline & & $5^{\circ}$ Exercício - O movimento \\
\hline & & $6^{\circ}$ Exercício - Direção do movimento \\
\hline & & $7^{\circ}$ Exercício - Novas relações \\
\hline & & $8^{\circ}$ Exercício - Estudo dos caracteres do objeto \\
\hline & & $9^{\circ}$ Exercício - O peso \\
\hline & & $10^{\circ}$ Exercício - A linha e suas direções \\
\hline \multirow{8}{*}{$2^{\circ} \mathrm{Dom}$} & \multirow[t]{8}{*}{ A esfera, o cubo, } & $1^{\text {a }}$ série $-1^{\circ}$ Exercício - Comparar a esfera com a bola \\
\hline & & $1^{\text {a }}$ série $-2^{\circ}$ Exercício - Comparar esfera e cubo \\
\hline & & $1^{\text {a }}$ série $-3^{\circ}$ Exercício - As arestas e os ângulos \\
\hline & & $1^{\text {a }}$ série $-4^{\circ}$ Exercício - O cilindro \\
\hline & & $1^{\text {a }}$ série - $5^{\circ}$ Exercício - Os três sólidos comparados \\
\hline & & $2^{\text {a }}$ série $-1^{\circ}$ Exercício - As faces do cubo \\
\hline & & $2^{\mathrm{a}}$ série $-2^{\circ}$ Exercício - As arestas do cubo \\
\hline & & $2^{\mathrm{a}}$ série $-3^{\circ}$ Exercício - O círculo \\
\hline
\end{tabular}

Fonte: Bastos (2011).

A escolha da bola como primeiro dom deve-se ao fato de que, "[...] firmando todos os brinquedos em uma base matemática, tem na superfície esférica da bola a mais simples e a mais perfeita forma dos objetos sólidos, na qual todas as outras formas se contêm" (BASTOS, 2011, p. 151, grifo nosso). A justificativa do ponto de partida de sua proposta apoia-se em princípios matemáticos, partindo da premissa da forma esférica como simples e perfeita.

De outra parte, a bola é o brinquedo considerado predileto das crianças, ou seja, Froebel une o lúdico da criança com os primeiros passos do ensino de matemática. Os exercícios elaborados com a bola compreendem a observação do próprio objeto, de suas propriedades aparentes, das posições de um objeto no espaço, do movimento, direção, velocidade, do peso da bola. Como exemplo, traz-se o 50 exercício proposto, referente ao movimento:

O objeto está em repouso, a bola colocada sobre a mesa; a criança segura o cordel. Contrastar a ideia de repouso e de movimento: $1^{\circ}$ Repouso; $2^{\circ}$ Ir para a direita; $3^{\circ}$ Ir para a esquerda; $4^{\circ}$ Subir; $5^{\circ}$ Descer; $6^{\circ}$ Avançar; $7^{\circ}$ Recuar; $8^{\circ}$ Ir, afastar-se; $9^{\circ} \mathrm{Vir}$, aproximar-se; $10^{\circ}$ Lentamente (para diante); $11^{\circ}$ Depressa, depressa (volta para atrás); $12^{\circ}$ Repouso (como termo do movimento). (BASTOS, 2011, p. 156).

O segundo dom é formado por três sólidos: esfera, cubo e cilindro, construídos da seguinte maneira: o diâmetro da esfera é igual a altura e ao diâmetro do cilindro e à aresta do cubo. Cada um dos sólidos tem um pequeno anel para enfiar-se um cordel de suspensão. A finalidade do brinquedo é analisar e comparar os objetos: a esfera tem a superfície toda esférica, o cilindro tem uma superfície curva e outras 
duas planas e o cubo tem todas as superfícies planas. A primeira série de exercícios tem o propósito de explorar, comparar, analisar os três sólidos na sua totalidade e, na segunda série de exercícios, o estudo direciona-se para as partes dos objetos, suas faces, linhas, ângulos, ou seja, a observação deve se fixar nas particularidades dos três sólidos, sempre propondo comparar similaridades e diferenças, como linhas retas e curvas, ângulos retos etc.

As séries de exercícios para o $2^{\circ}$ dom indicam claramente a marcha do estudo e exploração que parte do todo e segue para as partes, o chamado método analítico, amplamente divulgado no final do século XIX. O método analítico para o ensino da leitura - do todo para as partes - fundamenta-se, principalmente, nos moldes norteamericanos, ganhando adeptos e sendo empregado nas escolas modelos na capital do estado de São Paulo (MORTATTI, 2000). Na história da educação matemática, os métodos e os processos analítico e sintético podem ser mais bem compreendidos em Leme da Silva (2016) e Valente (2015).

Os próximos dons seguem a exploração das formas geométricas, mas o foco centra-se nas contagens, nos cálculos, como se apresenta a seguir:

Quadro 2 - Dons de Froebel ( $3^{\circ}$ ao $\left.6^{\circ}\right)$

\begin{tabular}{|c|c|c|}
\hline \multirow{10}{*}{ 3Dom } & \multirow[t]{10}{*}{ O cubo dividido em oito cubos } & $1^{\circ}$ Exercício - O todo e as partes \\
\hline & & $2^{\circ}$ Exercício - Os pequenos cubos \\
\hline & & $3^{\circ}$ Exercício - Ideia de fração (1/2 e 1/4) \\
\hline & & $4^{\circ}$ Exercício - Ideia de fração (1/8) \\
\hline & & $5^{\circ}$ Exercício - O sólido \\
\hline & & $6^{\circ}$ Exercício - As três dimensões do sólido \\
\hline & & $7^{\circ}$ Exercício - O volume \\
\hline & & $8^{\circ}$ Exercício - A estabilidade \\
\hline & & $9^{\circ}$ Exercício $-\mathrm{A}$ simetria \\
\hline & & $10^{\circ}$ Exercício - A simetria \\
\hline \multirow{8}{*}{$4^{\circ} \mathrm{Dom}$} & \multirow[t]{8}{*}{ Os prismas } & $1^{\circ}$ Exercício - Recapitulação \\
\hline & & $2^{\circ}$ Exercício - Análise da forma prismática \\
\hline & & $3^{\circ}$ Exercício - Observar características do prisma \\
\hline & & $4^{\circ}$ Exercício - Medindo por superposição \\
\hline & & $5^{\circ}$ Exercício - Construção com sete prismas \\
\hline & & $6^{\circ}$ Exercício - Construção com oito prismas \\
\hline & & $7^{\circ}$ Exercício - Construção com oito prismas \\
\hline & & $8^{\circ}$ Exercício - Construção com oito cubos \\
\hline $5^{\circ} \mathrm{Dom}$ & O cubo dividido em 27 cubos & $\begin{array}{l}\text { Construções com as } 39 \text { peças } \\
\text { Formas simétricas } \\
\text { Formas matemáticas } \\
\text { Quadrados iguais } \\
\text { Quadrados diferentes } \\
\text { Quadrados iguais e desiguais reunidos }\end{array}$ \\
\hline $6^{\circ} \mathrm{Dom}$ & 0 cubo dividido em 27 tijolinhos & Formas simétricas \\
\hline
\end{tabular}

Fonte: Bastos (2011). 
O conjunto dos objetos formado pelo $3^{\circ}$ até o $6^{\circ} \mathrm{dom}$ apresenta somente prismas, porém com diferentes formatos, cubos e paralelepípedos e em distintas quantidades. No $3^{\circ} \mathrm{dom}$, a proposta do cubo ser dividido em oito cubos menores permite o estudo das relações entre parte e todo, introduzindo as ideias das frações $1 / 2,1 / 4$ e $1 / 8$. O estudo da simetria passa a ser explorado de maneira livre no $3^{\circ}$ dom e segue nos demais. No $4^{\circ}$ dom, as construções sugeridas com as peças representam objetos familiares às crianças, como escada, tanque, túnel, caixa d'água, entre outras, de maneira a explorar a criatividade. No $5^{\circ} \mathrm{dom}$, a divisão em 27 tijolinhos é justificada por ser uma progressão natural em que cada das três dimensões é dividida em três partes iguais, o que produz $3 \times 3 \times 3=27$ partes ou pequenos cubos.

Interessante observar a exploração tanto das formas e das propriedades geométricas como dos cálculos de relação entre parte e todo, incluindo as frações, desde o início dos exercícios que abrangem contagem, ou seja, o brincar envolve, de forma integrada e intencional, conceitos da aritmética e da geometria. O sétimo e último dom introduz as formas triangulares nos brinquedos, que incluem triângulos retângulos, acutângulos e obtusângulos, além de isósceles, equiláteros e escalenos. 0 método de Froebel propõe várias tabuinhas de cada formato e com cores diferentes, de modo a oferecer uma variedade de formas geométricas, artísticas e de objetos usuais. Ao final, como sugestão, o autor recomenda que fique a cargo da professora analisar até que ponto devem ser estendidas as noções geométricas relativas ao quadrado, aos triângulos e às figuras que deles resultam.

Quadro 3 - Dom de Froebel ( $\left.7^{\circ}\right)$

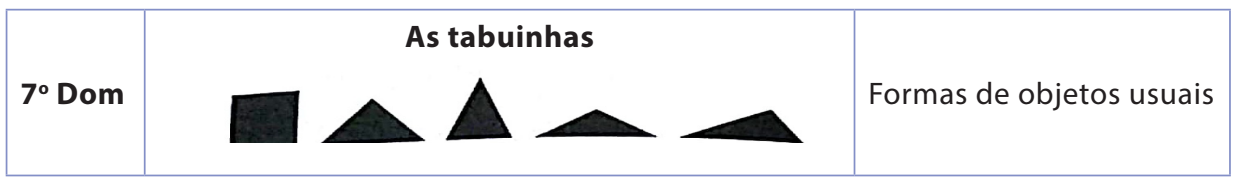

Fonte: Bastos (2011).

Aconselha-se que sejam construídos objetos usuais, como um ladrilho, um vaso de flores, uma torre, um pêndulo de relógio, dentre outros, como a ilustra a figura 2.

Figura 2 - Ladrilho

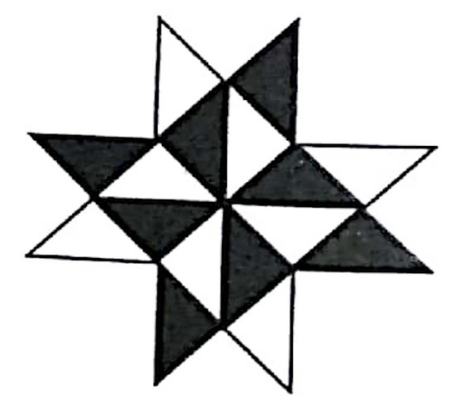

Fonte: Bastos (2011, p. 192).

O Manual, como já dito, dirige-se aos professores, às jardineiras, na designação de Froebel, com inúmeras sugestões, sempre organizadas em exercícios, com orientações detalhadas de como conduzir as atividades e as brincadeiras na sala de aula. 


\title{
Apropriações do método de Froebel que circulam no Paraná
}

No ano de 1906, foi inaugurado o primeiro Jardim de Infância público do estado do Paraná, anexo ao Ginásio Paranaense, em Curitiba, sob a direção da professora Maria Francisca de Miranda. Vale considerar que havia duas instituições mais antigas, o Jardim de Infância Emilia Erichsen, criado em 1862/1869, no Paraná, e o Jardim de Infância do Colégio Menezes Vieira, no Rio de Janeiro, em 1875, ambas instituições privadas de ensino.

Segundo Souza (2004), a criação do Jardim de Infância indica que a criança deveria se deparar com o ensino e se ocupar de diversões próprias à sua idade, concepções que não eram comuns na sociedade da época.

Do ponto de vista pedagógico, o trabalho ali desenvolvido tomou por base os princípios da proposta de Froebel, com relação ao contato das crianças com a natureza e o divino e ao uso de brincadeiras e de materiais diversificados. A organização do espaço e as formas de utilização dos jogos, sob ações orientadas pela jardineira e, também, com atividades livres, procuravam promover um ambiente estimulador.

\begin{abstract}
Os jogos nessa idade, ocupações espontâneas da criança, mostram uma tripla diferença: ou são imitações da vida e de seus fenômenos, ou são emprego do ensinado, da escola, ou são livres imagens e manifestações do espírito, de toda a espécie e em matéria de toda classe, segundo as leis contidas nos objetos e matérias do jogo investigando aquelas, seguindo-as e submetendoas às mesmas, segundo as contidas no homem mesmo, em seu pensamento e sentimento. (FROEBEL, 2001, p. 206).
\end{abstract}

Com o Jardim de Infância curitibano público, as propostas frobelianas ganharam acento em normativas educacionais. No Relatório do Dr. Laurentino de Azambuja, Delegado Fiscal da 1. Circunscrição Escolar, foi enfatizado o valor educativo das atividades realizadas, uma vez que "[...] o Jardim dessa capital é um bom centro educativo, modelado pelo método de Froebel" (PARANÁ, 1908, p. 65). A importância da proposta froebeliana, como opção metodológica, era valorizada pelos dirigentes do estado: "[...] educa-se por meio de brinquedos ou dons apropriados, cuja coleção bem combinada indica o esforço em prol da educação infantil" (PARANÁ, 1908, p. 64). Além disso, é explicado que:

\footnotetext{
Nesse estabelecimento o ensino é todo intuitivo; exercita-se a criança no emprego metódico dos órgãos dos sentidos, no conhecimento dos objetos, sua utilidade, nome, forma, cor; além de procurar corrigir certos defeitos peculiares à idade infantil, como a gagueira, o tatibitatismo e outros, assim como proporciona-se por meios de exercícios de ginástica racional a educação física, indispensável ao desenvolvimento dos órgãos e aparelhos em incipiente formação. (PARANÁ, 1908, p. 66).
}

A opção pela metodologia froebeliana na organização do trabalho do Jardim de Infância de Curitiba aconteceu em função da circulação e da propagação de ideias pedagógicas ancoradas em princípios de modernização e renovação pedagógica, e de modelos educativos já implementados em outros países, visto que: 
[...] tanto para a escola primária como para a educação infantil, era patente a presença da adoção do método intuitivo, e o programa para a escola infantil voltava para a lição das coisas, canto, recitação, desenho, entre outros conteúdos, fruto da repercussão internacional que perpassou também pelo Brasil. (SOUZA, 2004, p. 171).

Camara (2019) analisou, em sua tese, fotografias do Jardim de Infância de Curitiba, nas quais se identifica a presença da proposta de Froebel. Dentre elas, a fotografia da sala de aula do Jardim de Infância (figura 3), de 1910, permite, para além da análise das intenções normativas, aprofundar apropriações do método de Froebel na cultura escolar deste estabelecimento, por meio do registro de vestígios do ambiente pedagógico deste local.

Figura 3 - Fotografia de sala de aula do Jardim de Infância

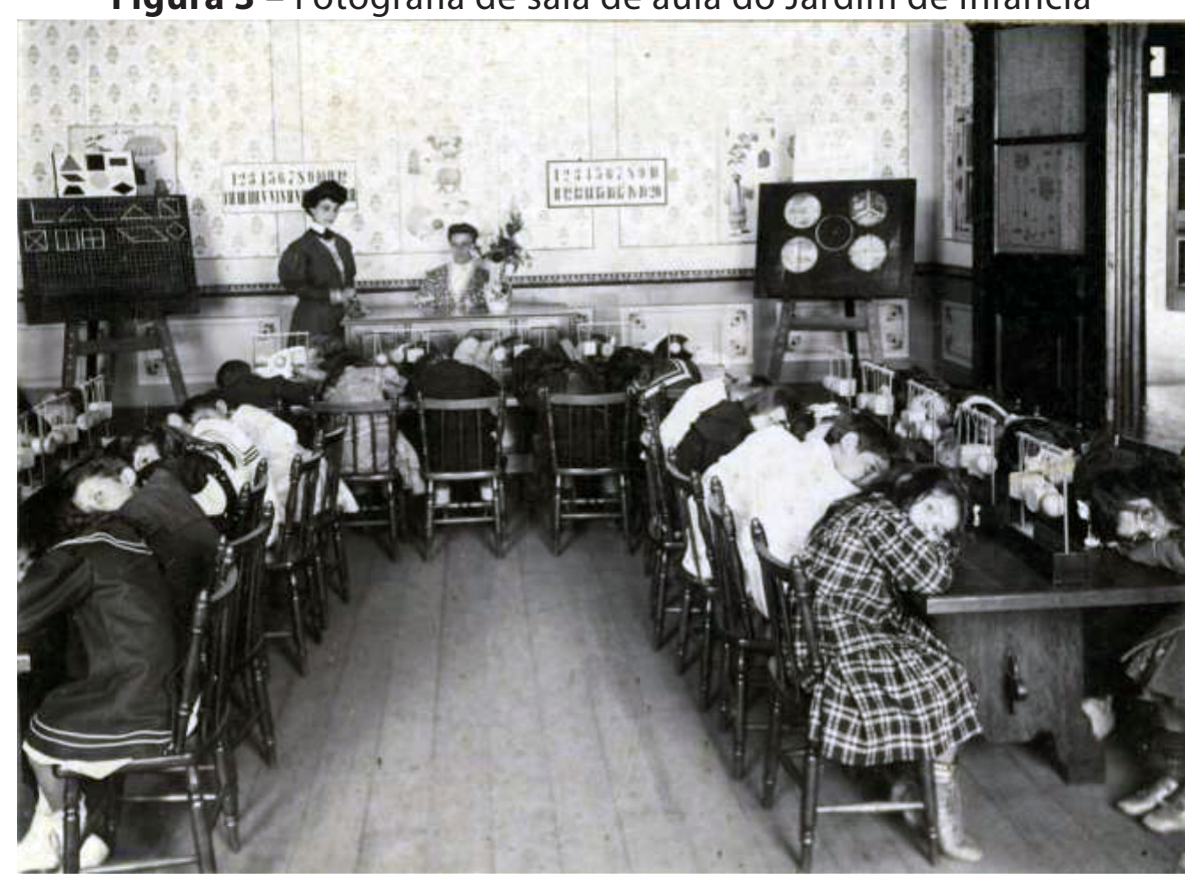

Fonte: Acervo do Museu Paranaense (MP) (1910).

Dentre os materiais didáticos, que fazem parte da cena, verificam-se um quadro negro quadriculado com formas geométricas representadas com pauzinhos, cartazes com formas geométricas, números, animais e outros, um quadro negro com quatro círculos e, sobre a mesa, cada criança tem um brinquedo formado por uma esfera, um cilindro e um cubo. Uma pluralidade de objetos didáticos que, efetivamente, se encontram na sala de aula.

A fotografia, juntamente com outros tipos de documentos e vestígios históricos, é uma importante fonte que pode auxiliar na leitura da dinâmica escolar de uma determinada época. Além disso, vale lembrar que "[...] a imagem não fala por si só; é necessário que as perguntas sejam feitas" (MAUAD, 1996, p. 10). Portanto, pode-se questionar: qual seria o material que se encontra em frente às crianças (figura 4) e quais atividades poderiam ser realizadas? Como foi desenvolvida a mediação da professora com as crianças? Enfim, são inúmeras as questões que podem ser levantadas. Assim, pretende-se superar o aspecto meramente ilustrativo, e ir em busca dos contextos mobilizados para o ensino naquele momento.

'Há o consentimento do Museu Paranaense para o uso desta fotografia no presente artigo. 
Figura 4 - Detalhe ampliado da fotografia

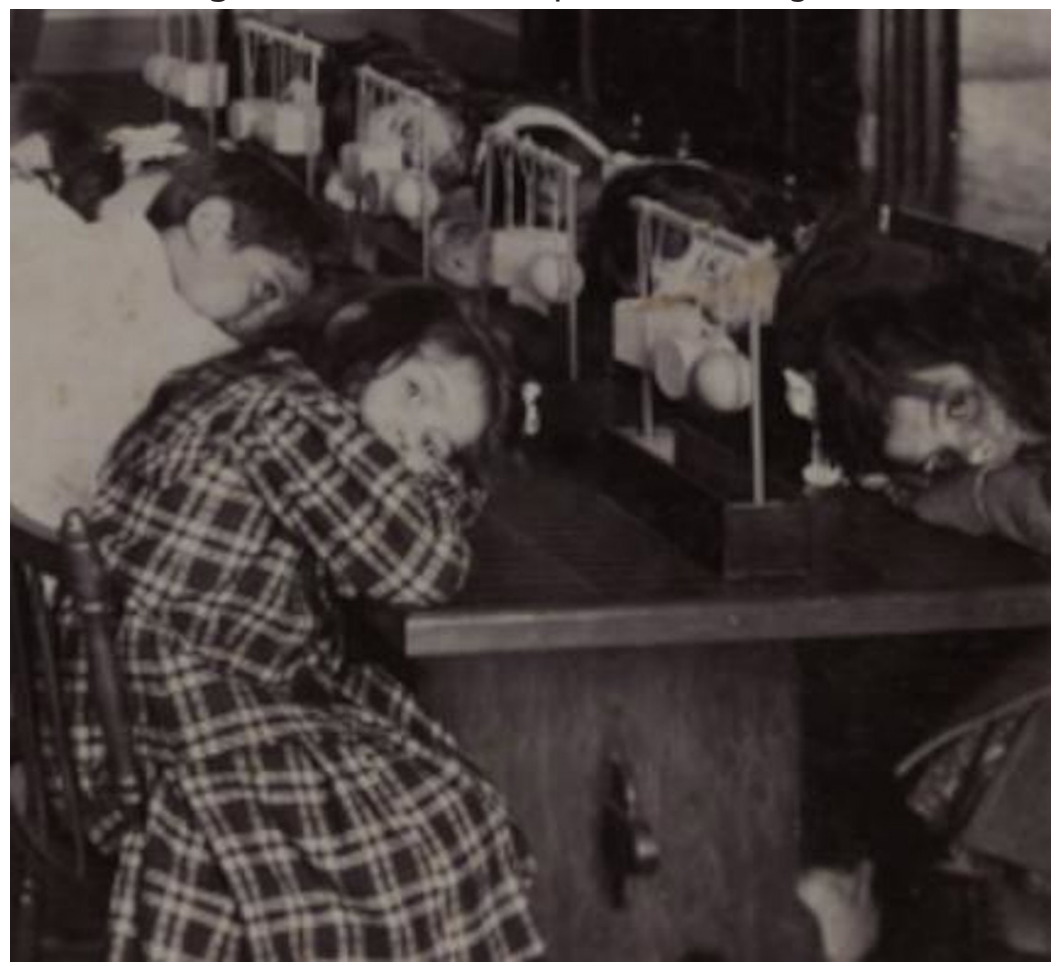

Fonte: Acervo do Museu Paranaense (MP).

O conjunto de objetos compartilhados entre uma dupla de crianças é formado por: esfera, cilindro e cubo. Tudo indica que se trata de um material que compõe a proposta elaborada por Friedrich Froebel quanto ao ensino do segundo dom, conforme apresentado anteriormente. Provavelmente, o uso do método froebeliano nas práticas do estabelecimento do Paraná aconteceu por conta da formação que a professora Maria Francisca de Miranda (diretora da Instituição) realizara em São Paulo no ano de 1904, para conhecer de perto a experiência do Jardim de Infância da Escola Normal Caetano de Campos (CAMARA, 2019).

\section{Apropriações do método de Froebel que circulam em São Paulo}

De acordo com Kuhlmann Jr. (1994), o primeiro Jardim de Infância público do Brasil foi instalado no estado de São Paulo, anexo à Escola Normal Caetano de Campos, durante a direção de Gabriel Prestes, político e intelectual. Destinado ao atendimento de crianças de 4 a 6 anos de idade, o Jardim de Infância foi inspirado no modelo Kindergarten, criado por Froebel. No mesmo ano em que foi inaugurado o Jardim de Infância, Gabriel Prestes editou a Revista do Jardim de Infância, com a intenção de tornar conhecida a metodologia utilizada neste segmento de ensino e, mais especificamente, organizar as principais ideias do sistema froebeliano, contribuindo, assim, para a criação e a melhoria de outros Jardins de Infância em São Paulo e em outros estados brasileiros (KUHLMANN JR., 1994).

As duas edições da Revista (1896 e 1897) tinham como propósito orientar e subsidiar as atividades das jardineiras. Ademais, elas procuravam fazer com que seus leitores conhecessem alguns manuais publicados no exterior e, em especial, nos Estados Unidos e na Itália. No primeiro número da Revista (1896) foram publicados o plano de organização do Jardim da Infância, instituído por F. Parker na Cook County Normal School, e o programa formulado pela Sra. Anna W. Devereaux, inspetora dos 
Jardins da Infância do Lowel Mass, nos Estados Unidos. No segundo volume, de 1897, foi apresentado o programa do Jardim de Infância da Itália por meio da transcrição da obra Frederico Froebel ed il suo sistema di Educazione, Napoles, por Amália de Rosa. Além destes manuais, há Pratical suggestions for kindergartners, de Jeanette R. Gregory, e In the child's word, de Emilie Poulsson; para exercícios de ginástica, brinquedos, contos e hinos: Music for the Kinder-Garten, de Eleonore Meervart, e Die Ruwegungsspiele und Lieder des Fröbel'fchen Kindergartens, de Fried Seidel. Assim, é possível verificar traduções e adaptações de programas de Jardins de Infância de outros países, o que representa relevante fonte de estudo a respeito das rotinas e das modificações realizadas na metodologia froebeliana em sua entrada no Brasil (ARCE, 2002).

Consta do volume I da Revista, a publicação de um relatório, extremamente formal, elaborado por Maria Ernestina Varella, inspetora do Jardim de Infância de São Paulo, em que apresentava um programa de ensino dividido em três períodos. Para Kuhlmann Jr. (1994), mesmo havendo certa flexibilidade e autonomia para as professoras, conforme indica Gabriel Prestes, havia um limite para a atuação, devido ao minucioso detalhamento das atividades. No entanto, as prescrições destas revistas representam, de qualquer forma, uma aproximação com as práticas desenvolvidas nos Jardins de Infância, de modo a testemunhar, em especial, os saberes matemáticos que as crianças vivenciavam em seu cotidiano.

O programa expõe as atividades cotidianas ou rituais, linguagem (conversação e conto), atividade física, música, dons froebelianos, modelagem, trabalho manual, brinquedos e jogos, desenho, entre outras. A cada período, as atividades eram retomadas e aprofundadas e, no caso específico dos dons de Froebel, eram introduzidos novos dons e aperfeiçoados os já trabalhados anteriormente.

Focando a presente análise no segundo dom, identificado na cena da fotografia do primeiro Jardim de Infância do Paraná, ele era indicado nos três períodos, conforme relatório apresentado na revista. No primeiro período, o segundo dom era trabalhado por meio da modelagem das representações da esfera, do cubo e do cilindro. No segundo período, ocorriam observações e comparações entre as formas, ou seja, as crianças tinham que observar superfícies planas e curvas, linha reta e curva, quadrado e círculo, já no último período, recapitulavam o que haviam estudado anteriormente.

No volume II da Revista, Gabriel Prestes escolhe explorar o programa de um Jardim de Infância italiano, justificando sua preferência pelo grande mérito do trabalho realizado naquele estabelecimento. As situações descritas com as crianças apresentam uma proposta de articulação entre as diferentes atividades que faziam parte do programa. Com o objetivo de melhor compreender a cena da fotografia, escolhem-se analisar as atividades relacionadas ao segundo dom e que, possivelmente, apresentaram algum tipo de influência na prática desenvolvida pela professora Maria Francisca de Miranda em terras paranaenses.

$\mathrm{Na}$ indicação da proposta italiana, a jardineira responsável pela turma, possivelmente, iniciava as atividades com um conto e, em seguida, realizava um exercício de conversação acerca das características da madeira. Após o desenvolvimento dessas atividades, ocorriam as passagens das caixas que continham o segundo dom. Para começar a primeira atividade, as crianças permaneciam sentadas e com as mãozinhas pousadas sobre a beira da mesa, indicação que nos leva à cena da aula do Jardim 
de Infância de Curitiba. Além dos momentos repetidos, conforme rotina diária estabelecida, as demais atividades também mostravam todo um ritual de desenvolvimento.

Em seguida, era indicado que a jardineira solicitasse que as crianças retirassem da caixa um objeto, parecido com a bola do primeiro dom e, por meio de conversação, realizavam-se questionamentos com o objetivo de elas compararem a bola de borracha coberta com lã (primeiro dom) com a esfera de madeira (segundo dom), fazendo com que chamassem o novo objeto de esfera e não de bola, como faziam no primeiro dom. Em seguida, as crianças suspendiam a esfera pelo cordel e a faziam girar, cantando "Girar, girar. Que o giro enxota o frio. Girar, girar. Num rodopio, sem descançar. Oh, sim, girar! Oh, sim, rodar!" (REVISTA..., 1897, p. 127).

$\mathrm{Na}$ atividade seguinte, era realizada a comparação da bola e da esfera com relação à forma, ao tipo de material, ao peso, à cor e ao movimento. No desenvolvimento das atividades, também era solicitado que as crianças colocassem a esfera na frente, atrás ou sobre a caixa e que a pegassem ora com a mão esquerda, ora com a mão direita, o que denota, inclusive, a preocupação com o desenvolvimento de compreensões sobre o espaço, lateralidade e ideias topológicas.

O objeto esférico de madeira também fazia parte de atividades físicas, quando a professora o empurrava com os pés para uma das crianças, e esta o empurrava para outra criança, até todas terem participado da brincadeira. Ao término do trabalho com a esfera, era introduzida a forma do cubo por meio da comparação com a esfera, seguindo uma estrutura muito similar com as atividades anteriores, embora fosse ampliada a complexidade dos exercícios.

As atividades indicadas para o segundo dom sugerem uma proposta de estudo articulada entre os diferentes saberes envolvidos. Não era recomendado o estudo isolado das formas geométricas. Gabriel Prestes (REVISTA...1897, p. 13) ressalta que as atividades realizadas durante a semana escolar deveriam se relacionar entre si, ou seja, "Umas devem derivar-se de outras ou, pelo menos, devem guardar entre si uma certa relação no correr da semana, sendo todas a aplicação da primeira lição da segunda-feira que é a narração". Deste modo, as formas geométricas do segundo dom estariam associadas à linguagem, elementos da natureza, corpo humano, etc., brincadeiras de adivinhação, música e ginástica. A proposta de estudo das três figuras geométricas (esfera, cubo e cilindro) para os primeiros anos de escolaridade esteve presente nas normativas do estado de São Paulo por mais de cinquenta anos, desde 1894 até 1949/50 (FRIZZARINI, 2014).

Apesar de Froebel ter elaborado a sua proposta para os Jardins da Infância, verifica-se que muitas de suas concepções eram apropriadas ao ensino primário, como o próprio Menezes de Vieira observa em seu Manual. No contexto paranaense, Dario Persiano de Castro Vellozo (1869-1937), professor de metodologia da Escola Normal de Curitiba, indicou o uso dos métodos de Froebel para o ensino primário no ano de 1907. Velozzo era carioca e mudou-se para Curitiba em 1885. No ano de 1899, assumiu o cargo de professor do Ginásio Paranaense e da Escola Normal, ao mesmo tempo em que atuava como colaborador, redator ou editor de revistas voltadas ao ensino. Ele se identificava com as questões metodológicas do magistério e defendia a escola moderna e a educação pública (SCHAFFRATH, 2014). Em assim sendo, a proposta de 
Froebel também ofereceu mudanças com relação às propostas pedagógicas no ensino primário.

\section{Considerações finais}

Por meio deste estudo, pode-se identificar a proximidade do Brasil com os estudos de vanguarda, advindos tanto da Europa como dos Estados Unidos. Para além da circulação internacional, o nosso país, de dimensão continental, também promoveu a circulação de diferentes vertentes de um mesmo método de ensino, o froebeliano. França, Estados Unidos e Itália dialogaram com apropriações brasileiras, em um primeiro momento restrita aos Jardins de Infância privados e, depois, ganhando acento nas instituições públicas.

Algumas das propostas de trabalho no Jardim de Infância da época analisada despontam-se como recursos didáticos fundamentais, como a decomposição do todo em partes e as possibilidades de aprendizagem a partir de elementos simples. Tais escolhas ancoravam-se nas ideias de Pestalozzi, tendo em conta que os indivíduos seriam dotados de uma força de intuição sensível e de uma consciência com relação a objetos ao seu redor, ou seja, a aprendizagem ocorreria pela educação dos sentidos. Desse modo, a proposta pedagógica de Froebel cria dons ou brinquedos para os primeiros passos de uma educação escolar que, além da intenção do desenvolvimento dos sentidos, primava pelo aspecto lúdico.

Ao longo da pesquisa, foi possível verificar que, apesar de Froebel ter elaborado a sua proposta para os Jardins da Infância, muitas de suas concepções eram indicadas também ao ensino primário. Este fato leva a crer que, provavelmente, suas propostas tenham oferecido mudanças com relação às práticas pedagógicas deste segmento de ensino. Além disso, as análises indicam que os dons froebelianos tenham se constituído objetos manipuláveis com intencionalidade educativa, em que os saberes matemáticos, especialmente o cálculo e as formas geométricas, ganham destaque. Portanto, considera-se que a História da Educação Matemática na infância necessita ser revisitada, trazendo novos objetos e novas interpretações.

\section{Agradecimentos}

O artigo constitui resultado parcial de Projeto de Pesquisa Edital Universal do Conselho Nacional de Desenvolvimento Científico e Tecnológico (CNPq), Projeto 406989/2018-4, sob a coordenação da primeira autora.

\section{Referências}

ARCE, A. Friedrich Froebel: o pedagogo dos jardins de infância. Petrópolis: Vozes, 2002.

BARBOSA, R. Obras completas de Rui Barbosa: reforma do ensino primário e várias instituições complementares da instrução pública: vol. X, 1883, tomo III. Rio de Janeiro: Ministério da Educação e Saúde, 1947. Disponível em: https://cutt.ly/YEd7IYe. Acesso em: 30 jun. 2020.

BASTOS, M. H. C. Manual para os jardins de infância: ligeira compilação pelo Dr. Menezes Vieira: 1882. Porto Alegre: Redes Editora, 2011.

BRASIL. Ministério da Educação. Base nacional comum curricular, 2018. Disponível em: https:// cutt.ly/UWCZwjg. Acesso em: 9 set. 2021. 
CAMARA, A. Saberes geométricos na educação primária paranaense: elementos das culturas escolares e da formação do cidadão republicano (1889-1946). 2019. 246 f. Tese (Doutorado em Educação) - Pontifícia Universidade Católica do Paraná, Curitiba, 2019. Disponível em: https:// cutt.ly/NEd7LCu. Acesso em: 9 set. 2021.

CONCEIÇÃO, G. L. Experts em educação: circulação e sistematização de saberes geométricos para formação de professores (Rio de Janeiro, final do século XIX). 2019. Tese (Doutorado em Ciências) - Escola de Filosofia, Letras e Ciências Humanas, Universidade Federal de São Paulo, Guarulhos, 2019. Disponível em: https://repositorio.unifesp.br/handle/11600/59847. Acesso em: 9 set. 2021.

FRIZZARINI, C. R. B. Do ensino intuitivo para a escola ativa: os saberes geométricos nos programas do curso primário paulista. 160 f. Dissertação (Mestrado em Ciências) - Escola de Filosofia, Letras e Ciências Humanas, Universidade Federal de São Paulo, Guarulhos, 2014. Disponível em: https:// repositorio.unifesp.br/handle/11600/46879. Acesso em: 31 ago. 2021.

FROEBEL, F. W. A. A educação do homem. Passo Fundo: UPF, 2001.

GONZALEZ. K. C. A. V. Concepções de infância: um estudo do manual para os jardins de infância do dr. Menezes Vieira (1882). 2020. Tese (Doutorado em Educação) - Universidade Federal de Santa Catarina, Florianópolis, 2020. Disponível em: https://repositorio.ufsc.br/ handle/123456789/216563. Acesso em: 31 ago. 2021.

KISHIMOTO, T. M. Os jardins de infância e as escolas maternais de São Paulo no início da república. Cadernos de Pesquisa, São Paulo, n. 64, p. 57-60, 1988. Disponível em: https://cutt.ly/ hWCCUG1. Acesso em: 31 ago. 2021.

KUHLMANN JR., M. O jardim da infância Caetano de Campos. In: REIS, M. C. D. (org.). "Caetano de Campos": fragmentos da história da instrução pública em São Paulo. São Paulo: Associação dos ex-alunos do IECC, 1994. p. 61-72.

LEME DA SILVA, M. C. Saberes geométricos e o método analítico no final do século XIX. Revista Diálogo Educacional, Curitiba, v. 16, n. 48, p. 301-319, 2016. DOI: https://doi.org/gvrg.

MATASCI, D. L'école républicaine et l'étranger: une historie internacionale des réformes scolaires en France 1870-1914. Lyon: Ens Éditions, 2015.

MAUAD, A. M. Através da imagem: fotografia e história interfaces. Tempo, Rio de Janeiro, v. 1, n. 2, p. 73-98, 1996. Disponível em: http://www.labhoi.uff.br/node/24. Acesso em: 31 ago. 2021.

MORTATTI, M. R. L. Os sentidos da alfabetização: São Paulo / 1876-1994. São Paulo: Ed. Unesp, 2000.

PARANÁ. Relatório de Laurentino de Azambuja, delegado fiscal da $10^{\circ}$ circunscrição escolar. Curitiba: Tipografia Paranaense, 1908.

REVISTA DO JARDIM DA INFÂNCIA. São Paulo: Typographia Espindola, Siqueira \& Comp., v. 1, 1896. Disponível em: https://cutt.ly/RWCBxQ3. Acesso em: 22 maio 2020.

REVISTA DO JARDIM DA INFÂNCIA. São Paulo: Typographia Espindola, Siqueira \& Comp., v. 2, 1897. Disponível em: https://cutt.ly/dWCBQcr. Acesso em: 22 maio 2020.

SCHAFFRATH, M. A. S. Os livros didáticos na Escola Normal de Curitiba (1876-1920): entre a universalidade e as singularidades da circulação da literatura pedagógica. 2014. Tese (Doutorado em Educação) - Pontifícia Universidade Católica do Paraná, Curitiba, 2014.

SOUZA, G. Instrução, o talher para o banquete da civilização: cultura escolar dos jardins de infância e grupos escolares do Paraná, 1900-1929. 2004. Tese (Doutorado em Educação) - Pontifícia Universidade Católica de São Paulo, São Paulo, 2004.

VALENTE, W. R. Como ensinar matemática no curso primário?: uma questão de conteúdos e métodos, 1890-1930. Perspectivas da Educação Matemática, Campo Grande, v. 8, n. 17, p. 192-207, 2015. Disponível em: https://cutt.ly/JWCNQLj. Acesso em: 22 maio 2020. 